\title{
Characterization of tebuconazole resistance in Botrytis cinerea from tomato plants in China
}

\author{
Can Zhang ${ }^{1 \dagger}$, Tengjiao $\mathrm{Li}^{1 \dagger}$, Lu Xiao', Shunli Zhou² and Xili Liư ${ }^{1,3^{*}}$
}

\begin{abstract}
Fungal pathogen Botrytis cinerea, the casual agent of gray mold of vegetables and fruits, has a high risk of developing resistance to fungicide. Tebuconazole, one kind of demethylation inhibitor (DMI) fungicides, has been increasingly applied for the control of tomato gray mold in China. However, very limited information is available on the resistance profile of $B$. cinerea to tebuconazole. In this study, the baseline sensitivity of $B$. cinerea to tebuconazole was determined based on 138 isolates from field sites having no history of DMI usage, with a mean $\mathrm{EC}_{50}$ value of $0.29 \mu \mathrm{g} / \mathrm{mL}$. Another 159 B. cinerea isolates collected in the greenhouse and field from 2011 to 2016 were demonstrated to have a shifted sensitivity to tebuconazole, with a mean $\mathrm{EC}_{50}$ value of $0.66 \mu \mathrm{g} / \mathrm{mL}$. $E C_{50}$ values of $10 \mathrm{~B}$. cinerea isolates with reduced sensitivity to tebuconazole were greater than $1.56 \mu \mathrm{g} / \mathrm{mL}$, and these reducedsensitive isolates had a fitness penalty in sporulation and conidial germination, but showed similar mycelial growth rate and pathogenicity with those of the sensitive isolates. Positive cross-resistance was observed only between tebuconazole and the other two DMls difenoconazole and prochloraz, but not between tebuconazole and the nonDMls iprodione, procymidone, or fludioxonil. In reduced-sensitive isolates, no amino acid variation was found in the BCCYP51 protein. When exposed to tebuconazole, the expression level of BCCYP51 increased in these reducedsensitive $B$. cinerea isolates as compared to sensitive ones, thus contributing to the reduced sensitivity of the pathogen to tebuconazole. Additionally, the nucleotide mutation observed in the $1200 \mathrm{bp}$ upstream region of BCCYP51 had no correlation with the development of fungicide resistance in B. cinerea isolates. These findings will be helpful for the understanding of DMI resistance mechnism in B. cinerea.
\end{abstract}

Keywords: Botrytis cinerea, DMI fungicide, Baseline sensitivity, Fitness, CYP51 expression

\section{Background}

Tomato (Solanum lycopersicum L.) is rich in vitamins and is cultivated throughout the world. Many diseases can affect tomato plants and result in decreased yield and quality. Gray mold, caused by Botrytis cinerea, is a devastating disease of tomato leading to serious economic losses worldwide (Williamson et al. 2007; Soylu

\footnotetext{
* Correspondence: seedling@cau.edu.cn

${ }^{\dagger}$ Can Zhang and Tengjiao Li contributed equally to this work.

'Department of Plant Pathology, China Agricultural University, Beijing 100193, China

${ }^{3}$ State Key Laboratory of Crop Stress Biology for Arid Areas, College of Plant Protection, Northwest A\&F University, Yangling 712100, China

Full list of author information is available at the end of the article
}

et al. 2010; Huang et al. 2011; Wang et al. 2013). B. cinerea infects not only tomato but also many other commercially important crops in the greenhouse and field, and is very difficult to control for several reasons (Williamson et al. 2007; Petrasch et al. 2019). This pathogen can survive as mycelia and/or conidia or sclerotia in crop debris or after the plant's growth season (Williamson et al. 2007). It can penetrate the surfaces of healthy plants by secreting a large number of cell walldegrading enzymes during the infection process (Kapat et al. 1998; Prins et al. 2000). The rapid gene mutation in $B$. cinerea make the pathogen easier to develop fungicide resistance in the field.

(c) The Author(s). 2020 Open Access This article is licensed under a Creative Commons Attribution 4.0 International License, which permits use, sharing, adaptation, distribution and reproduction in any medium or format, as long as you give appropriate credit to the original author(s) and the source, provide a link to the Creative Commons licence, and indicate if changes were made. The images or other third party material in this article are included in the article's Creative Commons licence, unless indicated otherwise in a credit line to the material. If material is not included in the article's Creative Commons licence and your intended use is not permitted by statutory regulation or exceeds the permitted use, you will need to obtain permission directly from the copyright holder. To view a copy of this licence, visit http://creativecommons.org/licenses/by/4.0/. 
Site-specific fungicides with different modes of action have been used for gray mold control worldwide. Evidence demonstrates that $B$. cinerea isolates have developed resistance to several fungicides, including dicarboximides, benzimidazole, phenylpyrrole, and hydroxyanilide (Myresiotis et al. 2007; Hu et al. 2016; Yin et al. 2018; Adnan et al. 2019). Sterol 14 $\alpha-$ demethylase inhibitors (DMIs) are a large class of compounds with demonstrated efficacy for controlling this and many other fungal diseases. They have been used for many years in the USA and Europe, and DMIresistant fungal pathogens have been reported in populations of not only B. cinerea (Stehmann and De Waard 1996) but also Colletotrichum cereale (Wong and Midland 2007), Mycosphaerella graminicola (Mavroeidi and Shaw 2005), Blumeria graminis f. sp. tritici (Godet and Limpert 1998), Venturia inaequalis (Köller et al. 1997), and Fusarium graminearum (Yin et al. 2009). However, the resistance status of DMI fungicide in B. cinerea isolates from tomato in China remains unknown.

DMI fungicides inhibit the cytochrome P450 sterol $14 \alpha$-demethylase, a critical enzyme encoded by the CYP51 gene that is essential for the biosynthesis of ergosterol in the fungal membrane (Senior et al. 1995; Dupont et al. 2012). The efficacy of DMIs usually decreases gradually compared with other site-specific fungicides that lose the efficacy due to point mutations in target proteins (Brent and Hollomon 2007). Previous studies have shown that DMI resistance was attributed to several mechanisms, including (i) targetsite non-synonymous alterations based on point mutations in the CYP51 gene (Wyand and Brown 2005; Leroux et al. 2007), (ii) increased expression of the target gene (Hamamoto et al. 2000; Schnabel and Jones 2001), (iii) enhanced energy-dependent efflux transport of the toxic compound (Reimann and Deising 2005), and (iv) increased copy numbers of the target gene and a transcriptional regulator of drug efflux pumps (Selmecki et al. 2008).

Tebuconazole, a typical DMI fungicide, has been registered and used for controlling tomato gray mold in China. Characterizing its resistance extent would provide important information for the government and growers to improve their gray mold chemical control programs. Moreover, fungicide resistance can be studied by analyzing parameters such as resistance and cross-resistance levels, or the fitness of fungicide-resistant isolates which play essential roles in determining the competitiveness of fungicide-resistant isolates in a pathogen population (Becher et al. 2010; Li et al. 2020). Thus, this study aimed to determine the sensitivity of $B$. cinerea isolates to tebuconazole, to examine fitness characters of sensitive and reduced-sensitive field isolates, and to investigate the molecular basis of tebuconazole resistance.

\section{Results}

Sensitivity of $B$. cinerea to tebuconazole in China

A total of $138 \mathrm{~B}$. cinerea field isolates from China with no history of DMI usage were used to establish the baseline sensitivity. The mean $\mathrm{EC}_{50}$ value exposed to tebuconazole was $0.29 \mu \mathrm{g} / \mathrm{mL}$ (Fig. 1a). The lowest $\mathrm{EC}_{50}$ value was $0.06 \mu \mathrm{g} / \mathrm{mL}$ and the highest was $1.01 \mu \mathrm{g} / \mathrm{mL}$. The frequency distribution of $\mathrm{EC}_{50}$ values of those isolates exhibited a unimodal curve with a positive skew, indicating that the data could be used as the baseline sensitivity of B. cinerea to tebuconazole (Fig. 1a).

The sensitivity to tebuconazole of 159 isolates collected in the greenhouse or field was further detected, with a mean $\mathrm{EC}_{50}$ value increased to $0.66 \mu \mathrm{g} / \mathrm{mL}$ (Fig. 1b). A non-normal distribution curve was displayed, with one major peak and one minor peak, indicating that $B$. cinerea populations had phenotypic subdivision in fungicide sensitivity (Fig. 1b). The median of the minor peak was $1.67 \mu \mathrm{g} / \mathrm{mL}$, with $\mathrm{EC}_{50}$ ranging from 1.56 to $1.78 \mu \mathrm{g} /$ $\mathrm{mL}$, suggesting that the isolates with $\mathrm{EC}_{50}>1.56 \mu \mathrm{g} / \mathrm{mL}$ might be resistant to tebuconazole. In total, the frequency of reduced-sensitive isolates was around 6.3\%, and 10 isolates showed reduced sensitivity to tebuconazole in all of the isolates tested (Fig. 1b).

\section{Control efficacy of tebuconazole on B. cinerea isolates with different sensitivities}

Two sensitive isolates (SF2-1 and SQ11) and two reduced-sensitive isolates (S11 and $\mathrm{FH} 30$, with $\mathrm{EC}_{50}$ $1.56 \mu \mathrm{g} / \mathrm{mL}$, the smallest value in the minor peak of Fig. 1b) were used to investigate the control efficacy of tebuconazole on gray mold of tomato fruit. All isolates were able to infect and develop lesions on tomato without fungicide treatment. Compared with the water-treated group, lesion development was decreased on fruit sprayed with fungicide, no matter for the sensitive or reduced-sensitive isolates. The control efficacy of tebuconazole for the reduced-sensitive isolates was between 12.7 and $18.3 \%$, while it was around $80 \%$ for the sensitive isolates (Fig. 2). The results demonstrated that the control efficacy of tebuconazole on sensitive $B$. cinerea isolates was significantly higher $(P<0.05)$ than that on reduced-sensitive isolates.

\section{Resistance level and stability of reduced-sensitive $B$. cinerea isolates to tebuconazole}

The resistance level and stability to tebuconazole were measured in six reduced-sensitive $B$. cinerea isolates. $\mathrm{EC}_{50}$ values were determined between the first and 10th generations on fungicide-free medium, and the resistance factor (RF; the ratio of the $\mathrm{EC}_{50}$ value of a reducedsensitive isolate to the mean value of baseline sensitivity) was calculated (Table 1). The majority of isolates maintained similar levels of RF. This was reflected as the 

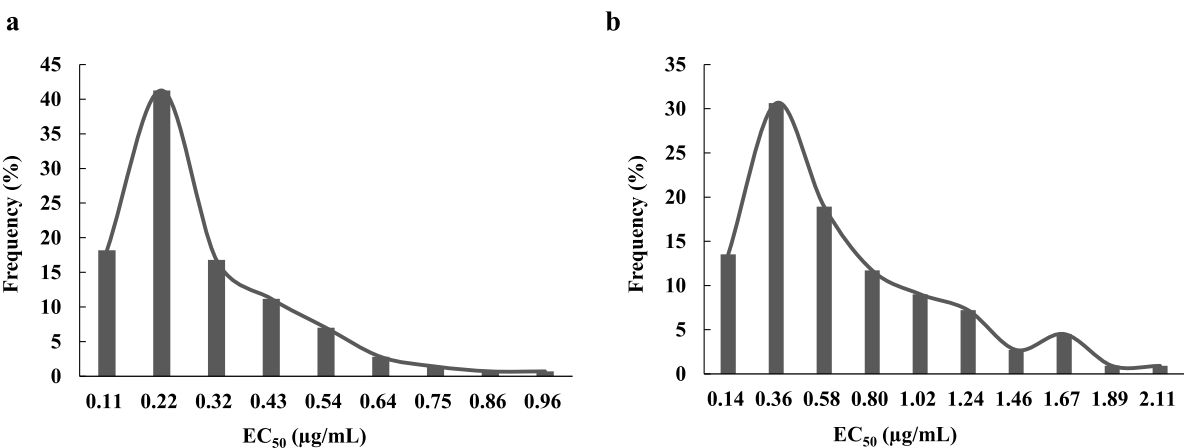

Fig. 1 Frequency distribution of effective concentrations for 50\% growth inhibition ( $\mathrm{EC}_{50}$ ) of tebuconazole on a 138 Botrytis cinerea isolates without usage of DMls and $\mathbf{b} 159$ isolates collected in the field and greenhouse from 2011 to 2016

factor of sensitivity change (FSC; the ratio of RF values at the 10th to the first transfer), which ranged from 0.80 to 1.04 .

\section{Colony growth of $B$. cinerea isolates with different sensitivities to tebuconazole}

For all the $B$. cinerea isolates, the optimal temperature for mycelial growth was $20^{\circ} \mathrm{C}$. The reduced-sensitive isolate D20 showed the highest mycelial growth rate in all the tested isolates whether at low or high temperatures (Table 2). The reduced-sensitive isolates S11 and D25 grew more slowly than others at all tested temperatures $(P<0.05 ;$ Table 2$)$. The other three reduced-sensitive isolates showed similar mycelial growth rate with that of sensitive isolates at each temperature. None of the $B$. cinerea isolates could grow at $37^{\circ} \mathrm{C}$. The results indicated no positive

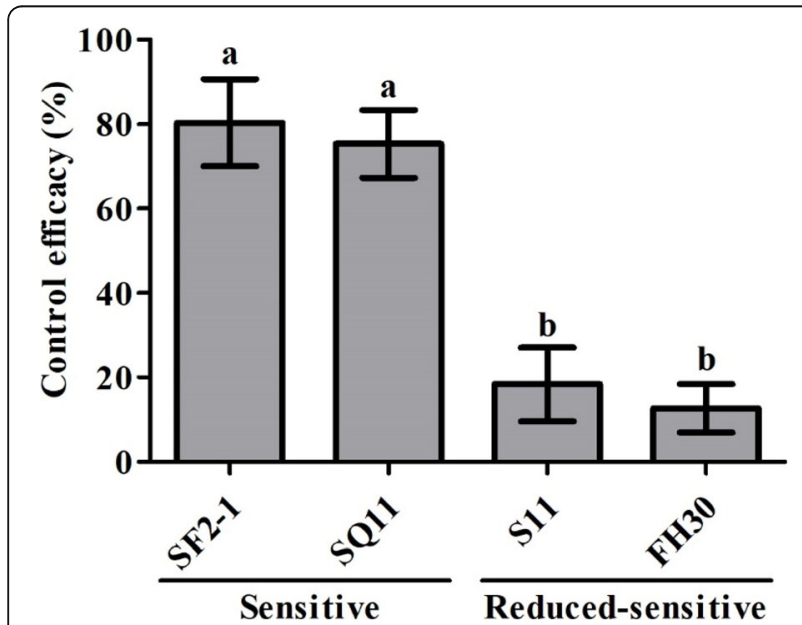

Fig. 2 Control efficacy of tebuconazole on gray mold of tomato fruit caused by two sensitive and two reduced-sensitive isolates. Columns and bars indicate mean \pm standard deviation (SD) from replicates; means with different letters are significantly different $(P<0.05)$ correlation between fungicide sensitivity and mycelial growth rate.

\section{Reduced-sensitive isolates had decreased conidia production and conidial germination rate}

Spore production was significantly decreased for the reduced-sensitive isolates compared to the sensitive isolates $(P<0.05$; Fig. 3a). The conidia number of the sensitive isolates ranged from $6.6 \sim 8.2 \times 10^{5} / \mathrm{cm}^{2}$, but decreased to around $1.2 \sim 4.4 \times 10^{5} / \mathrm{cm}^{2}$ in the reducedsensitive isolates (Fig. 3a). Compared with the sensitive isolates, all the reduced-sensitive isolates also had a reduced conidial germination rate. For example, the conidial germination rate was $89.3 \%$ in the sensitive isolate SF2-1 and $72.3 \%$ in the reduced-sensitive isolate SH330 (Fig. 3b). The lesion area produced on detached tomato fruit was not impaired in most reduced-sensitive isolates except D25 (Fig. 3c).

Table 1 Resistance level and stability of Botrytis cinerea isolates to tebuconazole after the $1^{\text {st }}$ and $10^{\text {th }}$ subculture on fungicidefree medium

\begin{tabular}{lllllll}
\hline Isolate $^{a}$ & \multicolumn{2}{l}{$\mathrm{EC}_{50}(\mu \mathrm{g} / \mathrm{mL})$} & & $\mathrm{RF}^{\mathrm{b}}$ & & $\mathrm{FSC}^{\mathrm{C}}$ \\
\cline { 2 - 3 } & $1^{\text {st }}$ & $10^{\text {th }}$ & & $1^{\text {st }}$ & $10^{\text {th }}$ & \\
\hline NJ2 & 0.032 & 0.036 & - & - & - \\
SF2-1 & 0.079 & 0.083 & & - & - & - \\
SQ11 & 0.097 & 0.091 & & - & - & - \\
S11 & 1.56 & 1.56 & & 5.38 & 5.38 & 1.00 \\
FH30 & 1.66 & 1.52 & & 5.72 & 5.24 & 0.92 \\
SH558 & 1.68 & 1.74 & & 5.79 & 6.00 & 1.04 \\
D20 & 1.76 & 1.86 & & 6.07 & 6.41 & 1.06 \\
SH330 & 1.84 & 1.70 & & 6.34 & 5.86 & 0.92 \\
D25 & 2.22 & 2.35 & & 7.66 & 8.10 & 1.06 \\
\hline
\end{tabular}

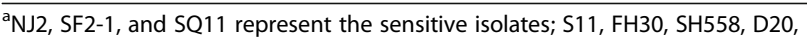
$\mathrm{SH} 330$, and D25 represent the reduced-sensitive isolates

${ }^{\mathrm{b}} \mathrm{RF}=$ resistance factor, the ratio of the $\mathrm{EC}_{50}$ of a reduced-sensitive isolate to the mean value of baseline sensitivity

${ }^{\mathrm{C}} \mathrm{FSC}=$ factor of sensitivity change, the ratio of $\mathrm{RF}$ values for $\mathrm{EC}_{50}$ at the $10^{\text {th }}$ to the $1^{\text {st }}$ transfer 
Table 2 The mycelial growth of Botrytis cinerea isolates under different temperature on YG medium without fungicide

\begin{tabular}{|c|c|c|c|c|c|}
\hline \multirow[t]{2}{*}{ Isolate $^{a}$} & \multicolumn{5}{|c|}{ Colony diameter $(\mathrm{mm})^{\mathrm{b}}$} \\
\hline & $4^{\circ} \mathrm{C}$ & $12^{\circ} \mathrm{C}$ & $20^{\circ} \mathrm{C}$ & $25^{\circ} \mathrm{C}$ & $30^{\circ} \mathrm{C}$ \\
\hline NJ2 & $5.4 \pm 0.4 c$ & $38.5 \pm 1.5 \mathrm{de}$ & $60.2 \pm 3.6 c$ & $53.5 \pm 3.4 c$ & $16.2 \pm 1.0 \mathrm{~b}$ \\
\hline SF2-1 & $6.3 \pm 0.3 b c$ & $54.5 \pm 0.5 \mathrm{a}$ & $65.1 \pm 3.6 \mathrm{bc}$ & $67.6 \pm 3.1 \mathrm{ab}$ & $23.8 \pm 2.6 \mathrm{a}$ \\
\hline SQ11 & $6.6 \pm 0.4 b$ & $55.4 \pm 0.4 a$ & $67.5 \pm 2.3 b$ & $71.1 \pm 1.7 \mathrm{ab}$ & $24.8 \pm 3.5 a$ \\
\hline S11 & $5.6 \pm 0.2 c$ & $32.3 \pm 2.1 \mathrm{f}$ & $34.5 \pm 1.5 \mathrm{e}$ & $37.2 \pm 3.0 d$ & $8.1 \pm 1.0 \mathrm{~d}$ \\
\hline $\mathrm{FH} 30$ & $5.5 \pm 0.5 c$ & $42.4 \pm 2.4 \mathrm{~cd}$ & $65.5 \pm 2.5 b c$ & $64.4 \pm 4.2 b$ & $12.9 \pm 1.0 \mathrm{C}$ \\
\hline SH558 & $5.8 \pm 0.3 b c$ & $46.4 \pm 2.8 b c$ & $63.1 \pm 3.0 \mathrm{bc}$ & $65.5 \pm 2.6 \mathrm{ab}$ & $23.1 \pm 2.0 \mathrm{a}$ \\
\hline D20 & $8.3 \pm 0.3 a$ & $55.4 \pm 3.6 \mathrm{a}$ & $75.1 \pm 3.8 \mathrm{a}$ & $72.1 \pm 4.6 \mathrm{a}$ & $25.2 \pm 2.0 \mathrm{a}$ \\
\hline $\mathrm{SH} 330$ & $5.9 \pm 0.4 b c$ & $49.6 \pm 1.8 b$ & $64.1 \pm 3.7 \mathrm{bc}$ & $67.5 \pm 3.2 \mathrm{ab}$ & $23.7 \pm 1.8 \mathrm{a}$ \\
\hline D25 & $5.5 \pm 0.5 c$ & $35.5 \pm 3.3$ ef & $42.8 \pm 2.7 d$ & $28.4 \pm 1.2 \mathrm{e}$ & $6.8 \pm 0.7 d$ \\
\hline
\end{tabular}

${ }^{a} \mathrm{NJ} 2, \mathrm{SF} 2-1$, and SQ11 represent the sensitive isolates; S11, FH30, SH558, D20, SH330, and D25 represent the reduced-sensitive isolates. None of the isolates could grow at $37^{\circ} \mathrm{C}$

${ }^{b}$ Values in a column indicate means \pm standard deviation (SD). Means with different letters are significantly different $(P<0.05)$

Cross-resistance of $B$. cinerea isolates to tebuconazole and other DMl fungicides

A total of $20 \mathrm{~B}$. cinerea isolates, including 10 sensitive and 10 reduced-sensitive isolates, were used in the evaluation of cross-resistance between tebuconazole and other DMI fungicides. Based on $\mathrm{EC}_{50}$ values, it showed a strong positive correlation between sensitivity to tebuconazole and to two other DMI fungicides, difenoconazole $(\rho=0.851, P<0.0001)$ and prochloraz $(\rho=0.734, P=$
0.0001) in B. cinerea (Fig. 4a, b). However, the sensitivity of those isolates to tebuconazole was not associated with sensitivity to iprodione, procymidone, or fludioxonil $(P>0.05$; Fig. 4c-e).

\section{Analysis of the expression level of $B C C Y P 51$ in sensitive and reduced-sensitive $B$. cinerea isolates}

No amino acid sequence variation of BcCYP51 protein was found in any of the tested isolates. To further
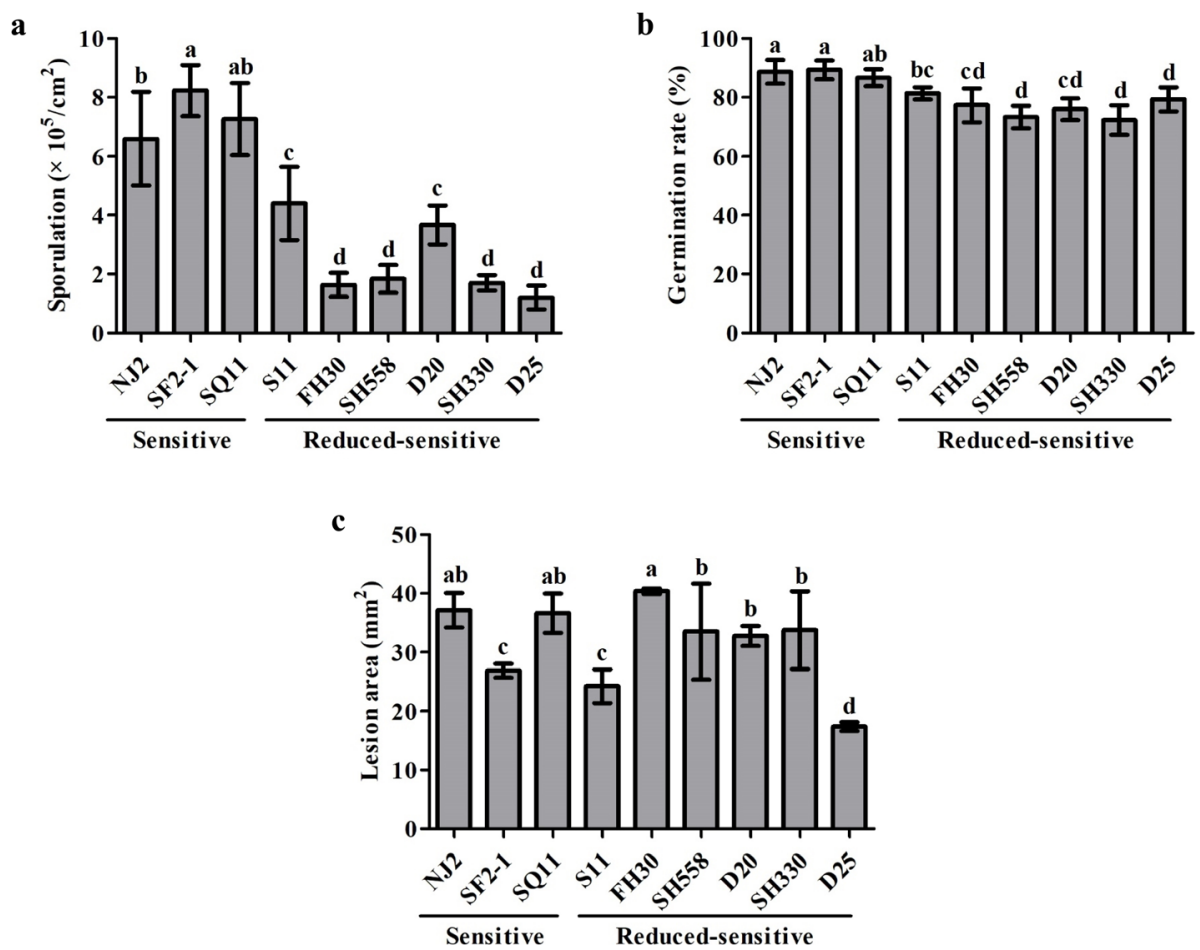

Fig. 3 Spore production (a), conidia germination rate (b), and pathogenicity on tomato fruit (c) of the sensitive and reduced-sensitive isolates of Botrytis cinerea 

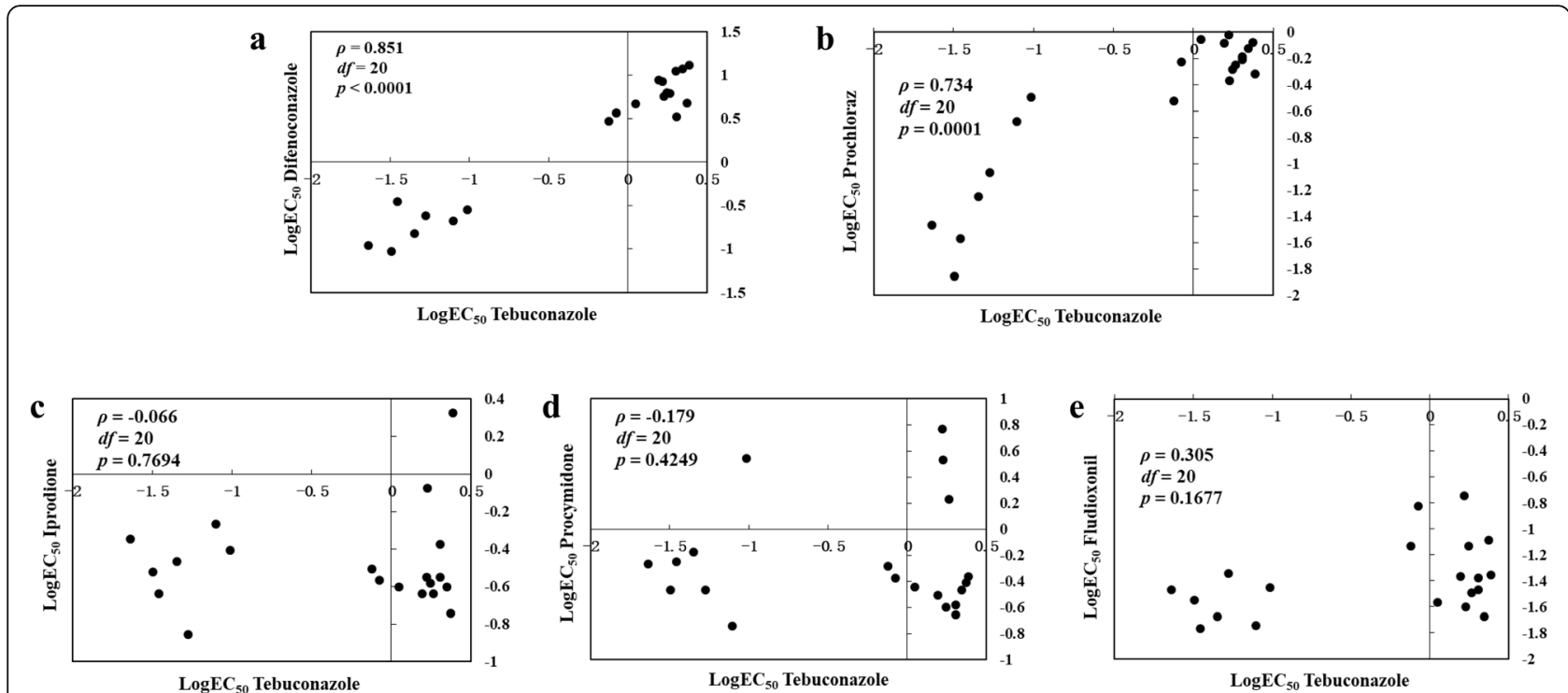

Fig. 4 Cross-resistance between tebuconazole and five fungicides by rank correlation analysis. a difenoconazole, b prochloraz, $\mathbf{c}$ iprodione, $\mathbf{d}$ procymidone, e fludioxonil. Data shown in logarithmic values of effective concentrations for $50 \%$ mycelial growth inhibition (log $\mathrm{EC}_{50}$ ) among Botrytis cinerea for fungicide combinations

explore the resistance basis, we investigated the expression levels of the BcCYP51 gene in B. cinerea isolates upon treatment with and without tebuconazole. For non-fungicide treated control, the mean expression levels of BcCYP51 in the sensitive and reduced-sensitive isolates were 1.42 and 1.46, respectively. The expression levels of $B c C Y P 51$ increased to 3.22 in the sensitive isolates and 24.32 in the reduced-sensitive isolates under $0.1 \mu \mathrm{g} / \mathrm{mL}$ of tebuconazole; and it increased to 5.30 and 45.92 under $2 \mu \mathrm{g} / \mathrm{mL}$ of tebuconazole, respectively. The induced expression level of $B c C Y P 51$ was almost 7.30to 8.38 -fold significantly upregulated in the reducedsensitive isolates compared to that in the sensitive isolates $(P<0.05$, Fig. 5). In addition, an insertion of a "GAGCAA" repeat was observed in the upstream region of the BcCYP51 gene, but it had no correlation with the fungicide resistance of the pathogens (unpublished data).

\section{Discussion}

Chemical fungicides play a crucial role in the management of gray mold. DMIs have been registered for use on some high-quality vegetables and fruits for several years in China. To determine whether there was a shift in $B$. cinerea sensitivity to DMIs with the continuous use of this kind of fungicides in the field, we first established the baseline sensitivity of $B$. cinerea to tebuconazole using isolates collected in the field without a history of DMIs usage. This data could be used to monitor sensitivity changes to tebuconazole in $B$. cinerea populations in China. Based on the above information, the sensitivity to tebuconazole of $159 \mathrm{~B}$. cinerea isolates collected in the greenhouse or field was further determined. The mean $\mathrm{EC}_{50}$ increased from 0.29 to $0.66 \mu \mathrm{g} / \mathrm{mL}$, indicating that the sensitivity shift did occur in $B$. cinerea. Moreover, we found that the isolates with $\mathrm{EC}_{50} \sim 1.56 \mu \mathrm{g} / \mathrm{mL}$ were also more difficult to control, represented by the smallest value of the minor peak in a curve graph, in which the frequency distribution of $B$. cinerea field

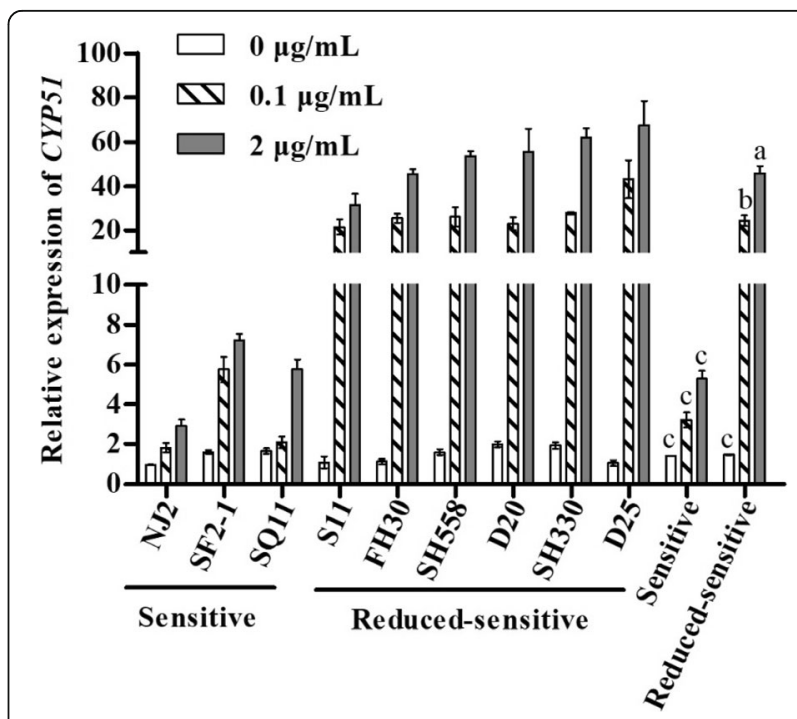

Fig. 5 Constitutive and fungicide-induced expression of BCCYP51 in the sensitive and reduced-sensitive isolates of Botrytis cinerea. Relative expression level of BCCYP51 was calculated by the $2^{-\Delta \Delta C t}$ method with actin gene as a reference. The expression level of BCCYP51 in each isolate was calculated relative to that of the isolate NJ2. Columns and bars indicate mean \pm standard deviation (SD) from replicates; means with different letters are significantly different $(P<0.05)$ 
isolates with different sensitivity to tebuconazole was displayed. This suggests the $\mathrm{EC}_{50}$ value of $1.56 \mu \mathrm{g} / \mathrm{mL}$ could be used as a criterion to judge tebuconazole resistance in further studies. However, the $\mathrm{EC}_{50}$ did not increase sharply, and tebuconazole might be used in the control of tomato gray mold with a rotation or mixtures of fungicides with different modes of action to delay resistance development.

Fitness plays an important role in the build-up of a fungicide-resistant population in a fungal pathogen, thus resistant isolates that have little or no fitness cost are more likely to persist in the field (Brent and Hollomon 2007; Chen et al. 2013). In this study, the B. cinerea isolates with reduced sensitivity to tebuconazole did have decreased sporulation and conidial germination, indicating that these isolates suffered some fitness cost. Other DMI-resistant mutants have also exhibited impaired fitness, such as C. truncatum mutants resistant to tebuconazole (Zhang et al. 2017), Monilinia fructicola mutants resistant to SYP-Z048 (Chen et al. 2012), and Aspergillus nidulans mutants resistant to imazalil (Vantuyl 1977). However, these reduced-sensitive $B$. cinerea isolates showed no significant differences in mycelial growth and especially pathogenicity compared with sensitive isolates. Similarly, isolates of $B$. cinerea resistant to carbendazim or boscalid have shown equivalent fitness to that of sensitive isolates (Fan et al. 2017). No significant differences in mycelium growth and virulence have also been found between procymidone/zoxamide-resistant and sensitive $B$. cinerea isolates from strawberry in Hubei, China (Adnan et al. 2019). A low fitness cost associated with fungicide resitance development is the reason that $B$. cinerea is considered as a high-risk pathogen (Fungicide Resistance Action Committee; www.frac.info). Furthermore, our results suggest that resistance to DMIs could spread in field populations of $B$. cinerea despite some fitness cost.

Positive cross-resistance was found between different DMIs in B. cinerea, but not between DMIs and nonDMIs (Fig. 4), which was as expected because crossresistance is usually related to the action mode of fungicides. A concern is that a relationship has been proposed between the development of resistance to agricultural and clinical DMIs. Reducing resistance risk management practices in agriculture could create a different risk scenario with increasing selection pressure resulting from, for example, higher doses or the accumulation of DMIs in the soil (Chowdhary et al. 2013). B. cinerea cannot infect humans, but it has a wide range of hosts, and some other pathogens on the same host could both infect plants and humans, such as Colletotrichum species. With increasing selection pressure, DMIs might become less effective on these diseases in the same region. Though evidence for a direct relationship between the development of drug resistance in agricultural and clinical practice has not been presented, it is indicated the treatment of Colletotrichum with agricultural fungicides may lead to the development of cross-resistance to clinical drugs (Castro et al. 2001; Serfling et al. 2007). Thus, risk management efforts for DMIs need to be maintained and monitored continuously.

There are several different mechanisms leading to DMI fungicide resistance. Amino acid alterations resulting from mutation of the CYP51 gene is a common resistance mechanism of fungi to DMIs (Sanglard and Odds 2002; Wyand and Brown 2005). According to previous studies, several points are responsible for DMI resistance, such as Y136F, V136A, I381V, D134G, and S524T (Cools et al. 2013). However, no amino acid substitution was detected in the reduced-sensitive isolates in this study. Resistance to DMIs might also involve the over-expression of ATP binding cassette $(\mathrm{ABC})$ or major facilitator superfamily (MFS) transporter-encoding genes (Hayashi et al. 2002; Kretschmer et al. 2009), but this possibility is very limited due to no cross-resistance being found between DMI and non-DMI fungicides. In filamentous fungi, particularly those infecting plants, more studies on the identification of ABC or MFS transporters, and their capacity to export azoles, could be conducted in the future.

As a mechanism of acquired resistance to fungicides, increased expression of the target gene, CYP51, is unique to the DMIs, which is also quite common in plant pathogens. The increased expression level of a constitutive gene is frequently caused by sequence alteration in the predicted regulatory region of the gene (Cools et al. 2013). In our study, we observed that the induced expression of CYP51 was associated with DMI resistance, but no alterations were found in its upstream regions (Fig. 5). The similar results were also reported previously, such as in C. truncatum (Zhang et al. 2017) or Alternaria sect. (Zhang et al. 2020). In addition, whether the increased expression of CYP51 was caused by its upstream transcription regulators (Hagiwara et al. 2017), an increased number of CYP51 copies (Osherov et al. 2001), or other mechanisms need to be investigated in the future. According to previous studies, fungicide resistance levels caused by the increased expression of the target gene are generally lower than those caused by amino acid alteration in fungicide target protein, which is consistent with the isolates acquired in the current work. However, a recent study found that M. graminicola isolates resistant to DMIs with a combination of target-site mutation and induced expression of CYP51 gene causes high levels of resistance to compounds specifically affected by mutations (Cools et al. 2012). Research needs to focus on the combination of different resistance bases, which could cause high-level resistance to DMI fungicides. 


\section{Conclusions}

Tebuconazole has been increasingly applied in the control of tomato gray mold in China, and a sensitivity shift was presented in B. cinerea isolates based on the detection results in the current study. To delay the development of fungicide resistance, DMIs could be used in the control of tomato gray mold with a rotation or mixtures of fungicides with different modes of action. Increased expression of the reported target gene of DMIs, CYP51, was associated with tebuconazole resistance in $B$. cinerea. Future research needs to focus on the combination of induced expression of the CYP51 gene with point mutations in CYP51 protein that might lead to high-level DMI resistance.

\section{Methods}

Isolates and culture conditions

$B$. cinerea isolates $(\mathrm{n}=138)$ used for the establishment of baseline sensitivity were selected from a pool of previously collected isolates from diseased tomato leaves or fruits in five provinces of China with no history of DMI usage. The 159 pathogen isolates used for the sensitivity monitoring were isolated from tomato in six provinces of China from 2011 to 2016 (Additional file 1: Table S1). There was a history of tebuconazole and triadimefon usages in the sampled locations from Shandong and Jiangsu; and other sampled locations in Henan, Beijing, Tianjin, and Shanghai were ever exposed to difenoconazole before. The isolates were cultured on yeast glucose agar medium (YG; yeast extract powder $5 \mathrm{~g}$, dextrose 18 g, agar $15 \mathrm{~g}$, distilled water to $1 \mathrm{~L}$ ) at $20^{\circ} \mathrm{C}$ under dark. After purification by single-spore isolation, all the isolates were identified as $B$. cinerea by polymerase chain reaction (PCR) using a previously reported primer pair $\mathrm{Bc}-\mathrm{f} / \mathrm{Bc}-\mathrm{r}$ (Fan et al. 2015). Mycelia of each isolate were maintained on YG slants under mineral oil and placed at $14{ }^{\circ} \mathrm{C}$ for long-term storage.

\section{Evaluation of sensitivity of $B$. cinerea isolates to tebuconazole}

The sensitivity to tebuconazole was evaluated by the effective concentration resulting in mycelial growth inhibition of $50 \%\left(\mathrm{EC}_{50}\right)$ in comparison with the control (without tebuconazole). A mycelium plug $(5 \mathrm{~mm}$ in diameter) taken from a three-day-old culture of each isolate was placed on the center of 90-mm-diameter YG plates containing tebuconazole at $0,0.25,0.5,1.25,2.5$, $5,10,20$, or $50 \mu \mathrm{L} / \mathrm{mL}$. For each isolate, there were three replicate plates per concentration. After incubation for 3 days in darkness at $20^{\circ} \mathrm{C}$, each colony diameter (minus $5 \mathrm{~mm}$ for the inoculated plug) was measured in two perpendicular directions. The $\mathrm{EC}_{50}$ values were graphically determined from the log-transformation of percentages of inhibition and regression against the natural logarithm of fungicide concentrations.

\section{Evaluation of control efficacy of fungicide}

Two sensitive isolates and two reduced-sensitive isolates with $\mathrm{EC}_{50} \sim 1.56 \mu \mathrm{g} / \mathrm{mL}$ were chosen as candidates to be tested for practical resistance to tebuconazole. Storebought tomato (cv. BeiBei) fruits of similar size were washed with distilled water and then dipped in $1 \%$ sodium hypochlorite for $1.5 \mathrm{~min}$, followed by rinsing twice with sterile distilled water, and air-dried. The detached fruits were treated with tebuconazole at the recommended label rate $(200 \mu \mathrm{g} / \mathrm{mL})$. The diluted fungicide was sprayed until run-off, and the fruit sprayed with distilled water was used as control. After the fruits were dried off in the air overnight at $20^{\circ} \mathrm{C}$, they were wounded by inserting a sterile toothpick to a $5 \mathrm{~mm} \times 2$ $\mathrm{mm}$ (diameter $\times$ depth) plug on each fruit. The conidial suspension was adjusted to $10^{5}$ conidia/mL and $50 \mu \mathrm{L}$ of the suspension was inoculated in each plug. The inoculated fruits were put into plastic boxes, and the boxes were covered with cling film to maintain high humidity. After 5 days at $20^{\circ} \mathrm{C}$ under a $12 \mathrm{~h}$ light/ $12 \mathrm{~h}$ dark cycle, the lesion area was evaluated for each fruit. There were five replicate fruits for each isolate, and the experiment was conducted twice independently. Finally, the following equation was used to calculate disease control efficacy: Control efficacy $=([$ lesion area of control - lesion area of fungicide treatment] / lesion area of control) $\times$ $100 \%$.

\section{Evaluation of the resistance stability to tebuconazole}

The stability of resistance to tebuconazole was evaluated in three sensitive (NJ2, SF2-1, and SQ11) and six reduced-sensitive isolates (S11, FH30, SH558, D20, SH330, and D25). These isolates were subjected to 10 successive transfers on fungicide-free YG medium. After each transfer, mycelial plugs excised from the periphery of three-day-old colonies were placed on a fresh fungicide-free medium. For each isolate, three replicate plates were used. The sensitivity of the first and 10th generations to tebuconazole was determined using the described method. The entire experiment was conducted twice.

\section{Colony growth of $B$. cinerea isolates under different temperature}

The nine isolates were used to determine the temperature sensitivity. Responses to a range of temperatures were determined by incubating the isolates from the leading edge of an actively growing colony to YG plates at $4,12,20,25,30$, and $37^{\circ} \mathrm{C}$ in darkness. After 3 days, the colony diameter was measured in triplicate for 
each isolate at each temperature. The experiment was conducted twice.

\section{Sporulation and conidial germination}

Isolates were grown on YG plates, and mycelial plugs excised from the margin of a three-day-old colony were placed on carrot agar medium (CA; carrot $200 \mathrm{~g}$, agar $15 \mathrm{~g}$, and distilled water to $1 \mathrm{~L}$ ) for conidia production. After incubation in darkness for 5 days, these cultures were treated with black light for 8 days to induce $B$. cinerea sporulation. The conidia were harvested by rinsing the sporulating colony in each plate with $20 \mathrm{~mL}$ of a $0.1 \%$ aqueous glucose solution and gently scraping the surface of the medium using a glass cell spreader. Conidia concentrations in the suspensions were calculated using a hemocytometer by microscope.

The conidial suspension was adjusted to $10^{5}$ to $10^{6}$ conidia/mL to evaluate the rate of germination. Briefly, $50 \mu \mathrm{L}$ of the suspension was spread onto depression slides placed on top of wet filter paper in a Petri dish. After incubation for $9 \mathrm{~h}$ at $20^{\circ} \mathrm{C}$ in darkness, 100 conidia were assessed per isolate for germination ability. Each isolate was represented by three replicate plates, and the experiment was performed twice.

\section{Pathogenicity test on tomato fruit}

Pathogenicity of $B$. cinerea was determined in the six isolates with reduced-sensitivity to tebuconazole and three tebuconazole-sensitive isolates as described above, but without fungicide treatment. The resulting lesion area on each fruit was measured at $72 \mathrm{~h}$ post-inoculation at $20^{\circ} \mathrm{C}$ under a photoperiod of $12 \mathrm{~h}$ light $/ 12 \mathrm{~h}$ dark. The entire experiments were performed twice.

\section{Cross-resistance of tebuconazole with other fungicides}

The sensitivity relationship was investigated between tebuconazole and two additional DMIs difenoconazole (concentration: $0,0.25,0.5,1.25,2.5,5,10$, and $50 \mu \mathrm{g} /$ $\mathrm{mL}$ ) and prochloraz (concentration: 0, 0.02, 0.05, 0.1, $0.5,1,5$, and $10 \mu \mathrm{g} / \mathrm{mL}$ ), and three fungicides of different action modes (iprodione, procymidone, and fludioxonil). The concentrations used were $0,0.05,0.1,0.5,2.5,5$, and $10 \mu \mathrm{g} / \mathrm{mL}$ for iprodione; $0,0.1,0.5,1,5,10$, and $50 \mu \mathrm{g} / \mathrm{mL}$ for procymidone; and $0,0.001,0.005,0.01$, $0.05,0.25,1$, and $10 \mu \mathrm{g} / \mathrm{mL}$ for fludioxonil. The sensitivity assay was conducted using the aforementioned mycelial growth inhibition assay method. Each combination of isolate and fungicide at each concentration was represented by three replicate plates, and the experiment was conducted twice.

\section{Cloning and sequencing of BCCYP51}

Based on the genome of $B$. cinerea, the primer pair BcCYP51-F (5' -TGCGATGGGGATTCTTGAAG-3') and
BcCYP51-R (5'-TTATCGTCGCTCCCAAGCTAC-3') were designed for the amplification of $B c C Y P 51$ from the sensitive and reduced-sensitive isolates. PCR reactions were performed in $25-\mu \mathrm{L}$ volumes using Taq DNA Polymerase E (TransGen Biotech Co., Beijing, China) following the manufacturer's recommendations. The amplified PCR products were verified by electrophoresis and purified using a gel extraction kit (TransGen Biotech), followed by cloning into the pEASY-T1 simple plasmid transformed in Escherichia coli (TransGen, Beijing, China). BcCYP51 inserted into the pEASY-T1 vector was sequenced at Beijing Tsingke Biotech Co., Ltd. using vector primers M13F (5'-ACTGGCCGTCGTTTTAC-3') and M13R (5'-GTCCTTTGTCGATACTG-3'). DNAM AN software (version 6.0; Lynnon Biosoft Bioinformatic Solutions) was used to compare the sequences of the reduced-sensitive isolates with those of sensitive ones.

\section{Determination of the expression level of BcCYP51}

Reverse transcription-quantitative PCR (RT-qPCR) was performed to investigate whether $B c C Y P 51$ was highly induced in isolates with reduced sensitivity to tebuconazole, using the methods developed by Zhang et al. (2017). Briefly, each isolate was incubated in a $150-\mathrm{mL}$ Erlenmeyer flask containing $80 \mathrm{~mL}$ of YG liquid medium. After 3 days of incubation at $20^{\circ} \mathrm{C}$ on a rotary shaker at $150 \mathrm{rpm}$, tebuconazole at each concentration was added to three of the six flasks for each isolate. Two concentrations of 0.1 and $2 \mu \mathrm{g} / \mathrm{mL}$ were used for all isolates. After $24 \mathrm{~h}$, mycelia were harvested by vacuum filtration for RNA extraction. Total RNA was extracted by the SV Total RNA Isolation Kit (Promega, Beijing, China). The RNA was treated with DNase (TaKaRa, Beijing, China) and used for cDNA synthesis with the PrimeScrip RT Reagent Kit with gDNA Eraser (TaKaRa, Beijing, China).

The ABI7500 sequence detection system (Applied Biosystems, USA) was used to conduct RT-qPCR in a $20 \mu \mathrm{L}$ reaction volume with the SYBR Premix Dimer Eraser Kit (TaKaRa, Beijing, China). The following program were used for the RT-qPCR analysis by three biological replications: $95^{\circ} \mathrm{C}$ for $30 \mathrm{~s}$; followed by 40 cycles of $95^{\circ} \mathrm{C}$ for $5 \mathrm{~s}$, $60^{\circ} \mathrm{C}$ for $30 \mathrm{~s}$; and $72^{\circ} \mathrm{C}$ for $34 \mathrm{~s}$. Primers used for RTqPCR were BcCYP51-QF/QR (5'-ATTTGGTGCT GGCAGACATAGA-3'; 5'-GTGAATAAACTTGCGTA ATCGGTA-3') for the BcCYP51 gene and Actin-QF/QR (5'-CTGGTC GTGATTTGACTGATTA-3'; 5' GATTGACTGGCGGTTTGG-3') for the reference gene actin. The relative quantities (RQs) of products were calculated using the $2^{-\Delta \Delta \mathrm{Ct}}$ method (Livak and Schmittgen 2001). Three independent experiments were conducted.

\section{Analysis of upstream sequence of $B C C Y P 51$}

To explore the molecular basis of the increased expression of $B c C Y P 51$ in reduced-sensitive isolates, its 
upstream sequence was amplified to determine whether there was any insert or other variations. The primer pair BcCYP51-UF (5'-GGGACTTATGGAAGGACG-3') and BcCYP51-UR (5'-AGTTGACCGCTGCGAAAT-3') was used for the described PCR amplification.

\section{Supplementary information}

Supplementary information accompanies this paper at https://doi.org/10. 1186/s42483-020-00064-9.

Additional file 1: Table S1. Background data regarding the Botrytis cinerea isolates in China.

\section{Abbreviations}

ABC: ATP binding cassette; BcCYP51: Botrytis cinerea cytochrome P450 stero 14a-demethylase; CA: Carrot agar medium; D134G: Substitution from aspartic acid to glycine at codon 134 of BcCYP51; DMI: Sterol 14a-demethylase inhibitor; $\mathrm{EC}_{50}$ : Effective concentration at which mycelium growth is inhibited by $50 \%$; FSC: Factor of sensitivity change, the ratio of RF values at the 10th to the first transfer; I381V: Substitution from isoleucine to valine at codon 381 of BCCYP51; MFS: Major facilitator superfamily; PCR: Polymerase chain reaction; RT-qPCR: Reverse transcription-quantitative PCR; RF: Resistance factor, the ratio of the $\mathrm{EC}_{50}$ value of a reduced sensitive isolate to the mean value of baseline sensitivity; S524T: Substitution from serine to threonine at codon 524 of BcCYP51; SD: Standard deviation; V136A: Substitution from valine to alanine at codon 136 of BcCYP51; Y136F: Substitution from tyrosine to phenylanaline at codon 136 of BCCYP51; YG: Yeast glucose agar medium

\section{Acknowledgments}

Not applicable.

\section{Authors' contributions}

$X \mathrm{~L}$ and $C Z$ designed the research. $C Z, L X$, and $T L$ performed the research. $C Z$, $T L$, and SZ analyzed the data. CZ and XL wrote the manuscript. All authors read and approved the final manuscript.

\section{Funding}

This study was supported by the National Key Research and Development Programs of China (2016YFD0201003, 2016YFD0201305), and also partially supported by the National High Technology Research and Development Program of China (No. 2012AA101502).

\section{Availability of data and materials}

Not applicable.

\section{Ethics approval and consent to participate}

Not applicable.

\section{Consent for publication}

Not applicable.

\section{Competing interests}

The authors declare that they have no competing interests.

\section{Author details}

'Department of Plant Pathology, China Agricultural University, Beijing

100193, China. ${ }^{2}$ College of Agronomy and Biotechnology, China Agricultural University, Beijing 100193, China. ${ }^{3}$ State Key Laboratory of Crop Stress Biology for Arid Areas, College of Plant Protection, Northwest A\&F University, Yangling 712100, China.

Received: 17 March 2020 Accepted: 24 July 2020

Published online: 30 August 2020

\section{References}

Adnan M, Hamada MS, Hahn M, Li GQ, Luo CX. Fungicide resistance of Botrytis cinerea from strawberry to procymidone and zoxamide in Hubei. Chin Phytopathol Res. 2019;1:17.
Becher R, Hettwer U, Karlovsky P, Deising HB, Wirsel SG. Adaptation of Fusarium graminearum to tebuconazole yielded descendants diverging for levels of fitness, fungicide resistance, virulence, and mycotoxin production. Phytopathology. 2010;100:444-53.

Brent KJ, Hollomon DW. Fungicide resistance: the assessment of risk. Brussels: FRAC; 2007.

Castro LGM, da Silva LC, Guarro J, Gene J, Heins-Vaccari EM, de Freitas Leite RS, et al. Phaeohyphomycotic cyst caused by Colletotrichum crassipes. J Clin Microbiol. 2001;39:2321-4

Chen F, Liu X, Schnabel G. Field strains of Monilinia fructicola resistant to both $M B C$ and DMI fungicides isolated from stone fruit orchards in the eastern United States. Plant Dis. 2013;97:1063-8.

Chen FP, Fan JR, Zhou T, Liu XL, Liu JL, Schnabel G. Baseline sensitivity of Monilinia fructicola from China to the DMI fungicide SYP-Z048 and analysis of DMl-resistant mutants. Plant Dis. 2012:96:416-22.

Chowdhary A, Kathuria S, Xu J, Meis JF. Emergence of azole-resistant Aspergillus fumigatus strains due to agricultural azole use creates an increasing threat to human health. PLoS Pathog. 2013;9:e1003633.

Cools HJ, Bayon C, Atkins S, Lucas JA, Fraaije BA. Overexpression of the stero 14a-demethylase gene (MgCYP51) in Mycosphaerella graminicola isolates confers a novel azole fungicide sensitivity phenotype. Pest Manag Sci. 2012; 68:1034-40.

Cools HJ, Hawkins NJ, Fraaije BA. Constraints on the evolution of azole resistance in plant pathogenic fungi. Plant Pathol. 2013;62:36-42.

Dupont S, Lemetais G, Ferreira T, Cayot P, Gervais P, Beney L. Ergosterol biosynthesis: a fungal pathway for life on land? Evolution. 2012;66:2961-8.

Fan F, Hamada MS, Li N, Li GQ, Luo CX. Multiple fungicide resistance in Botrytis cinerea from greenhouse strawberries in Hubei Province. Chin Plant Dis. 2017;101:601-6.

Fan X, Zhang J, Yang L, Wu M, Chen W, Li G. Development of PCR-based assays for detecting and differentiating three species of Botrytis infecting broad bean. Plant Dis. 2015:99:691-8.

Godet F, Limpert E. Recent evolution of multiple resistance of Blumeria (Erysiphe) graminis f. sp. tritici to selected DMl and morpholine fungicides in France. Pestic Sci. 1998;54:244-52.

Hagiwara D, Miura D, Shimizu K, Paul S, Ohba A, Gonoi T, et al. A novel Zn ${ }_{2}-C_{s_{6}}$ transcription factor AtrR plays a key role in an azole resistance mechanism of Aspergillus fumigatus by co-regulating cyp51A and cdr1B expressions. PLoS Pathog. 2017;13:e1006096.

Hamamoto H, Hasegawa K, Nakaune R, Lee YJ, Makizumi Y, Akutsu K, et al. Tandem repeat of a transcriptional enhancer upstream of the sterol 14 alpha-demethylase gene (CYP51) in Penicillium digitatum. Appl Environ Microbiol. 2000;66:3421-6.

Hayashi K, Schoonbeek HJ, De Waard MA. Expression of the ABC transporter BcatrD from Botrytis cinerea reduces sensitivity to sterol demethylation inhibitor fungicides. Pestic Biochem Physiol. 2002;73:110-21.

Hu MJ, Cox KD, Schnabel G. Resistance to increasing chemical classes of fungicides by virtue of "selection by association" in Botrytis cinerea. Phytopathology. 2016;106:1513-20.

Huang R, Li GQ, Zhang J, Yang L, Che HJ, Jiang DH, et al. Control of post-harvest Botrytis fruit rot of strawberry by volatile organic compounds of Candida intermedia. Phytopathology. 2011;101:859-69.

Kapat A, Zimand G, Elad Y. Biosynthesis of pathogenicity hydrolytic enzymes by Botrytis cinerea during infection of bean leaves and in vitro. Mycol Res. 1998; 102:1017-24.

Köller W, Wilcox WF, Barnard J, Jones AL, Braun PG. Detection and quantification of resistance of Venturia inaequalis populations to sterol demethylation inhibitors. Phytopathology. 1997;87:184-90.

Kretschmer M, Leroch M, Mosbach A, Walker AS, Fillinger S, Mernke D, et al. Fungicide-driven evolution and molecular basis of multidrug resistance in field populations of the grey mould fungus Botrytis cinerea. PLoS Pathog. 2009:5:e1000696.

Leroux P, Albertini C, Gautier A, Gredt M, Walker AS. Mutations in the CYP51 gene correlated with changes in sensitivity to sterol 14 alpha-demethylation inhibitors in field isolates of Mycosphaerella graminicola. Pest Manag Sci. 2007:63:688-98.

Li Y, Tsuji SS, Hu M, Câmar MPS, Michereff SJ, Schnabel G, et al. Characterization of difenoconazole resistance in Lasiodiplodia theobromae from papaya in Brazil. Pest Manag Sci. 2020;76:1344-52.

Livak KJ, Schmittgen TD. Analysis of relative gene expression data using real-time quantitative PCR and the $2^{-\Delta \Delta C T}$ method. Methods. 2001;25:402-8. 
Mavroeidi VI, Shaw MW. Sensitivity distributions and crossresistance patterns of Mycosphaerella graminicola to fluquinconazole, prochloraz and azoxystrobin over a period of 9 years. Crop Prot. 2005;24:259-66.

Myresiotis CK, Karaoglanidis GS, Tzavella-Klonari K. Resistance of Botrytis cinerea isolates from vegetable crops to anilinopyrimidine, phenylpyrrole, hydroxyanilide, benzimidazole, and dicarboximide fungicides. Plant Dis. 2007;91:407-13.

Osherov N, Kontoyiannis DP, Romans A, May GS. Resistance to itraconazole in Aspergillus nidulans and Aspergillus fumigatus is conferred by extra copies of the A. nidulans P-450 14a-demethylase gene, pdmA. J Antimicrob Chemother. 2001;48:75-81.

Petrasch S, Knapp SJ, Van Kan JAL, Blanco-Ulate B. Grey mould of strawberry, a devastating disease caused by the ubiquitous necrotrophic fungal pathogen Botrytis cinerea. Mol Plant Pathol. 2019;20:877-92.

Prins TW, Tudzynski P, von Tiedemann A, Tudzynski B, Ten Have A, Hansen ME, et al. Infection strategies of Botrytis cinerea and related necrotrophic pathogens. In: Kronstad J, editor. Fungal Pathology. Dordrecht: Springer; 2000. p. 33-64.

Reimann S, Deising HB. Inhibition of efflux transporter-mediated fungicide resistance in Pyrenophora tritici-repentis by a derivative of $4^{\prime}$-hydroxyflavone and enhancement of fungicide activity. Appl Environ Microbiol. 2005;71: 3269-75.

Sanglard D, Odds FC. Resistance of Candida species to antifungal agents: molecular mechanisms and clinical consequences. Lancet Infect Dis. 2002;2:73-85.

Schnabel G, Jones AL. The 14 alpha-demethylase (CYP51A1) gene is overexpressed in Venturia inaequalis strains resistant to myclobutanil. Phytopathology. 2001:91:102-10.

Selmecki A, Gerami-Nejad M, Paulson C, Forche A, Berman J. An isochromosome confers drug resistance in vivo by amplification of two genes, ERG11 and TAC1. Mol Microbiol. 2008;68:624-41.

Senior IJ, Hollomon DW, Loeffler RST, Baldwin BC. Sterol composition and resistance to DMl fungicides in Erysiphe graminis. Pestic Sci. 1995;45:57-67.

Serfling A, Wohlrab J, Deising HB. Treatment of a clinically relevant plantpathogenic fungus with an agricultural azole causes cross-resistance to medical azoles and potentiates caspofungin efficacy. Antimicrob Agents Chemother. 2007;51:3672-6.

Soylu EM, Kurt S, Soylu S. In vitro and in vivo antifungal activities of the essential oils of various plants against tomato gray mold disease agent Botrytis cinerea. Int J Food Microbiol. 2010;143:183-9.

Stehmann C, De Waard MA. Sensitivity of populations of Botrytis cinerea to triazoles, benomyl and vinclozolin. Eur J Plant Pathol. 1996;102:171-80.

Vantuyl JM. Genetic aspects of resistance to imazalil in Aspergillus nidulans. Neth J Plant Pathol. 1977:83:169-76.

Wang J, Xia XM, Wang HY, Li PP, Wang KY. Inhibitory effect of lactoferrin against gray mold on tomato plants caused by Botrytis cinerea and possible mechanisms of action. Int J Food Microbiol. 2013;161:151-7.

Williamson B, Tudzynski B, Tudzynski P, Van Kan JAL. Botrytis cinerea: the cause of grey mould disease. Mol Plant Pathol. 2007;8:561-80.

Wong FP, Midland SL. Sensitivity distributions of California populations of Colletotrichum cereale to the DMI fungicides propiconazole, myclobutanil, tebuconazole, and triadimefon. Plant Dis. 2007:91:1547-55.

Wyand RA, Brown JKM. Sequence variation in the CYP51 gene of Blumeria graminis associated with resistance to sterol demethylase inhibiting fungicides. Fungal Genet Biol. 2005;42:726-35.

Yin WX, Adnan M, Shang Y, Lin Y, Luo CX. Sensitivity of Botrytis cinerea from nectarine/cherry in China to six fungicides and characterization of resistant isolates. Plant Dis. 2018;102:2578-85.

Yin Y, Liu X, Li B, Ma Z. Characterization of sterol demethylation inhibitor-resistant isolates of Fusarium asiaticum and $F$ graminearum collected from wheat in China. Phytopathology. 2009;99:487-97.

Zhang C, Diao Y, Wang W, Hao J, Imran M, Duan H, et al. Assessing the risk for resistance and elucidating the genetics of Colletotrichum truncatum that is only sensitive to some DMl fungicides. Front Microbiol. 2017;8:1779.

Zhang Y, Zhou Q, Tian P, Li Y, Duan G, Li D, et al. Induced expression of CYP51 associated with difenoconazole resistance in the pathogenic Alternaria sect. On potato in China. Pest Manag Sci. 2020;76:1751-60.

\section{Ready to submit your research? Choose BMC and benefit from:}

- fast, convenient online submission

- thorough peer review by experienced researchers in your field

- rapid publication on acceptance

- support for research data, including large and complex data types

- gold Open Access which fosters wider collaboration and increased citations

- maximum visibility for your research: over $100 \mathrm{M}$ website views per year

At BMC, research is always in progress.

Learn more biomedcentral.com/submissions 